\title{
OPTIMIZATION OF LOAD NORMS FOR TRANSFRONTIER WATER BODIES TAKING INTO ACCOUNT NATURAL PROCESSES OF SELF-PURIFICATION
}

\author{
Dr. A.I. Shishkin, professor \\ Saint Petersburg State Technical University, Russia \\ Dr. L.A. Mosur, D.Sc. \\ Harris Group International Project and construction, Russia
}

\begin{abstract}
In the paper is used the systems approach to justification and optimization of norms of the load on the transboundary water bodies. Special attention was given to evaluation of the factors determining the norms of load on the natural water systems for individual transboundary water bodies. The effects of the pollutant transformation in the water bodies are taken into account. The algorithm of attribution of quotas to various kinds of man-caused load along entire length of the water body in question is offered. The concrete methods of meeting the environmental norms for the priority-driven types of pollutants. It is offered to introduce the norms attribution basing on environmental and emission approaches and taking into account the use of the best technologies for industrial and natural systems.
\end{abstract}

KEY WORDS: accumulating capacity, trophiclevel, hydrochemical characteristics, basin normalization, normalization of effluents discharge standards, emission standards, interindustry, natural background level, integrated, transfrontier water basin, considering the environmental capacity.

The main reason of normalization of industrial, domestic and agricultural effluents discharge standards taking into consideration their mutual interference is the selection of optimum water management system and, correspondently, the optimum plan of water protection actions at the basin level or the part of it. This in turn determines the preset environmental standards of the water body.

The approaches to the load norms for transfrontier water bodies are dependent of the whole series of factors. First of all it is necessary to evaluate the accumulating capacity of the water body along the whole length of it. For this end the water body prehistory connected with the particularities and the type of effluents accumulation is studied. The basis of it has to be the regular monitoring of hydrological, microbiological, hydrochemical characteristics at certain hydrological regimes. But until present there is no unified methodological, instrumental measurement and regulatory basis practically for any European transfrontier water body. Though some attempts to create it were undertaken for Rhine, Danube and other water bodies. In papers $(1,2)$ were examined the principles and methods of intergovernmental basin normalization.

The present paper is the follow-up of the said methods as applied to the transfrontier water bodies with the prevailing impact from the pulp and paper industry. 
In spite of evident progress in the field of normalization of effluents discharge standards for certain industries and specific enterprises the problem of interindustry basin normalization has become very acute. In the first place this is due to exceeding of concentration standards for considerable number of hydrochemical characteristics as well as water pollution indices (WPI) in large areas of water bodies. This leads to the ambiguity of effluent discharge standards requirements for of the enterprises located in the pollution zones with regard to some characteristics or water pollution indices. The decisions on individual enterprises have to be made as a part of general water protection program of the basin on the whole taking into consideration its extent and importance.

At present have appeared the preconditions for practical implementation of the environmental normalization system at interindustry basin level as well as at intergovernmental level for transfrontier water bodies.

One of the most illustrative examples is the basin Saima - Vuoksa - Ladoga - Neva - Gulf of Finland. In Saima basin are located several large Finnish pulp and paper mills. In Vuoksa basin is located also one of the largest Russian pulp and paper mill - Svetogorsk P\&PM as well as some smaller enterprises belonging to other industries. The development of industrial facilities in Vuoksa basin is connected with the necessity to normalize the load considering the background created by the group of Finnish pulp and paper mills.

The requirements for discharge of pulp and paper mills effluents in Russia and Finland differ considerably until present. In the framework of the Helsinki commission recommendations some rapprochement of positions was observed but practically the approaches to the effluent discharge standard normalization did not change with the Russian side. This led to the situations when in the section line of Vuoksa river the elevated natural background level was observed for a series of indices (lignin, hydrogen sulfide, dimethylsulfide, turpentine, oil products, methylmercaptan etc.), specific for pulp and paper industry effluents. The same situation is found in the internal national water bodies at administrative frontiers of districts and regions.

As has shown the Russian long-term practice of normalization of effluents discharge standards the formal assignment of effluents discharge limits at discharge standard level or at the background level (in case if $C_{\phi i}>$ discharge standard $d_{i}$ ) does not bring the desired result neither for the enterprise - water user (payments fro discharge beyond the limits are extremely high), nor from the point of view of water quality in the water body (water quality deteriorated continuously).

The most justified way to achieve the preset water quality standards is the integrated management of water resources on the basis of environmental and economic optimization of the process and water protection actions for the basin on the whole. In this case is applicable the basin principle of transfrontier water resources management with optimum distribution of quotas by integrated and specific pollution indices for industrial, domestic and agricultural production.

The water protection program has to take into consideration the zoning of the water body into zones with comparatively constant hydrological characteristics and zones with jumping basic parameters. The graphs of interconnection of the flow rate and the average flow velocity as well as annual graphs of flow rate in the given sections.

In accordance with the diagram of the transfrontier water basin lengthwise there are the groups of sections with certain limitations for water quality. The linear dependence of the quality in each section on all discharges upstream is observed.

$$
C_{j}=C_{j 0}-\sum a_{i j} C_{c m !},
$$

where $a_{j i}$-conformable impact matrix;

$C_{j 0}$ - water quality index in the absence of discharges, e.g. amount of dissolved oxygen; 
$C_{c m i}$ - amount of pollutants introduced in each $i$-th point into the stream.

The linear dependence is assurned between the cost of water protection actions and the concentration of substances in each $\mathrm{i}$-th point of discharge.

$$
P_{\mathrm{i}}=\text { const }_{\mathrm{i}}-\hat{P}_{,} C_{\mathrm{cm} i},
$$

where $\hat{P}_{1}$ - component of specific expense vector.

For a series of practical tasks the optimization diagram may be reduced to the form

$$
\begin{aligned}
& \hat{P} C_{c m} \rightarrow \max , \\
& A C_{c m} \leq C_{0}-C_{n \delta \kappa} \quad C_{c m} \geq 0,
\end{aligned}
$$

where $C_{n \partial \kappa}$ - limit level of the water quality index.

In the general case the problem has to be considered as nonlinear for the dependence between the cost of water protection actions and the concentration of pollutants at the discharge point is nonlinear and the self-purification processes are such that the pollutants from different sources participate in these processes non-additively.

Considering the water quality as discontinuous variable within limits of the water body section under investigation it can be assumed that at the topmost the water quality is determined by the only point of discharge. For each possible quality level in this section are determined appropriate water protection actions. At the next section downstream for the given quality level is established such a system of water protection actions for the second discharge outlet, that would allow the minimum cost of these actions for the first and the second discharge outlets. Thus, for each purity level at the second section may be found the water protection system having minimum cost and meeting the requirements for water quality at the previous stage. In the similar way is found the optimum water protection system for three, four and $n$ sections. And at each n-th stage are used the calculation results of the previous stage, i.e. the optimum system for (n-1) initial sections for each possible quality level at (n-1)-th section.

The particular feature of the approach under consideration is that as one problem is solved the additional data on the possible optimum solutions at other required water quality levels appear.

The option of the upper rigid limit of effluents predetermines the conditions on which the variations of the water body parameters are not taken into consideration and the standards are established in anticipation of the worst case.

The second option assumes the use of maximum allowable concentrations (PDK) of substances in the given water body stations as criteria and maximum allowable concentrations are the "rigid" standards and must not be violated under no circumstances.

Another probabilistic approach is being developed which admits that the concentration of given substance in the environment must not exceed the established $\mathrm{PDK}_{61}$ for the given basin more than $n$ times a year and never exceed the value of $\mathrm{PDK}_{62}$. In this case the following probabilistic problems of the water protection optimization may be solved. It is necessary to find out:

1. Which are the minimum expenses required to maintain the water quality:

- at the average not lower than $C_{l}$ level;

- with specified probability $p \leq 1$ not lower than $C_{2}$ level;

- at the average $C_{1}$ and with probability $p \leq 1$ not lower than $C_{2}\left(C_{2}>C_{1}\right)$

2 . With the given pecuniary or facility limitations (for the system of water protection actions):

- at what $C_{l}$ level may be maintained the average water quality;

- with what probability $p$ may be maintained water quality above given $C_{2}$ level. 
Thus the optimization problems may be considered as the expense minimization and the anticipated effect maximization.

On the whole in order to meet the basin standards may be use three types of water protection actions:

1. Streamlining the production technologies reducing the amount and the number of pollutants after main process.

2. Upgrading the local and off-site treatment facilities.

3. Actions connected with the water body itself.

The major attention at present and assuredly in the future will be focused at the first type of actions characteristic of the efficiency of the technologies as well as helping to master international and national emission standards. In new social and economic conditions the normalization in Russia has to take into account specific features of industries and the principles of international approaches to normalization pollutant discharge with effluents, which meets the requirements of the Russian national plan of environment protection. The emission standards mean establishment of specific values of discharge for certain indices for certain industries.

To the industries for which the emission standards are elaborated to the considerable degree belong first of all the pulp and paper industry.

The international and national environmental legislation abroad in countries with advanced pulp and paper industries is based on the technological normalization of specific discharge of pollutants ( $\mathrm{kg} / \mathrm{t}$ of product) for certain types of product and encouragement of actions aimed at prevention of pollutant formation in the main process or its minimization.

For implementation of such approach were developed the specific pollutant discharge norms for the products meeting the requirements of "best available technology". With such approach to the normalization the technical level of development assures the achievement of the regulated pollution level, but requires certain investments. Simultaneously with the limits for the discharge of pollutants are described the technical achievement the implementation of which allow to meet the discharge level.

The recommended limitation norms for pollutants discharge with effluents of pulp and paper mills for countries of Eastern and Western Europe-members of Helsinki Convention, Russia included, were developed for sulfite and sulfate pulp production. These norms of pollutant discharge (see Table 1) are set forth in Recommendations 17/8 "Reduction of discharge from the kraft pulp production" and 17/9 " Reduction of discharge from the sulfite pulp production" and are well known to the specialists through published papers (3).

According to these two Recommendations of HELCOM the requirements for the conditions of discharge of effluents formed in the bleached and non-bleached pulp production are ruled by four indices: $\mathrm{COD}, \mathrm{AOH}$ (absorbable organic halogens), total phosphorus, total nitrogen for enterprises commissioned before 1997 -"old" and after 1997 -"new" or "old ones" which had raised the output by $50 \%$ and more.

At present are expected similar HELCOM Recommendations for production of mechanical pulp, thermo-mechanical pulp, secondary fiber pulp, chemical-thermo-mechanical pulp as well as for production of paper and cardboard.

For European Union countries with advanced pulp and paper industry the recommended list of regulated discharge indices for enterprises meeting the principles of the "best available technology" have much in common with HELCOM Recommendations but is larger and supplemented with other indices. Thus, the specific effluents discharge from the production of bleached kraft pulp is ruled by six indices (kg/ADMT): COD -10-23; $\mathrm{BOD}_{5}-0,3-1,5$; suspended matters $-0,6-2,0 ; \mathrm{AOH}-0,0-0,25$; total nitrogen $0,1-0,25$; total phosphorus $-0,01$ 0,03 . The pollutants present in effluents of pulp and paper mills may be classified in several groups by their origin. This will permit to consider the possible ways to reduce the pollutant 
KALMAR ECO-TECH'01

Leachate and Wastewater Treatment with High-Tech and Natural systems

KALMAR, SWEDEN, November 26-28, 2001

discharge account for them in substantiation of updated List of priority indices for the control of impact of the pulp and paper industry effluents on the water bodies.

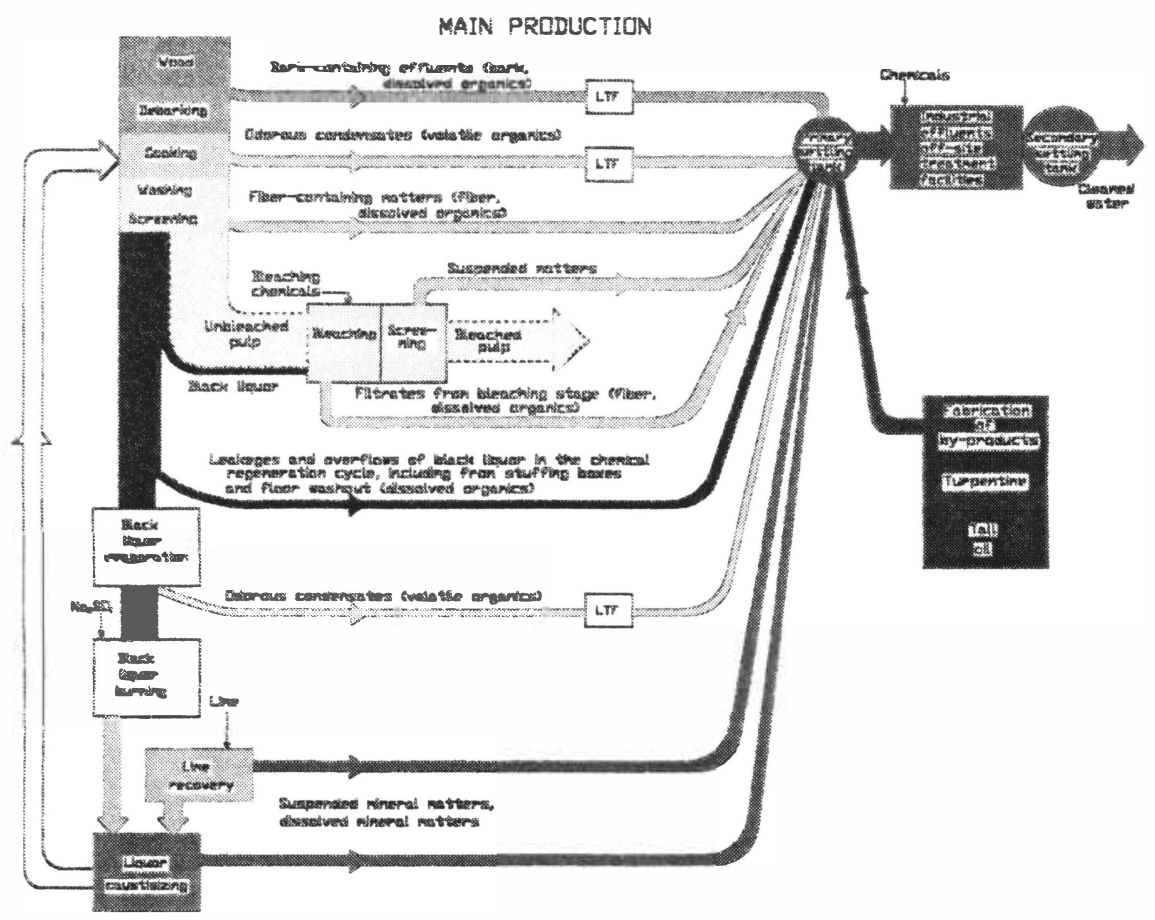

AUXUUARY PRODUCTEDA:

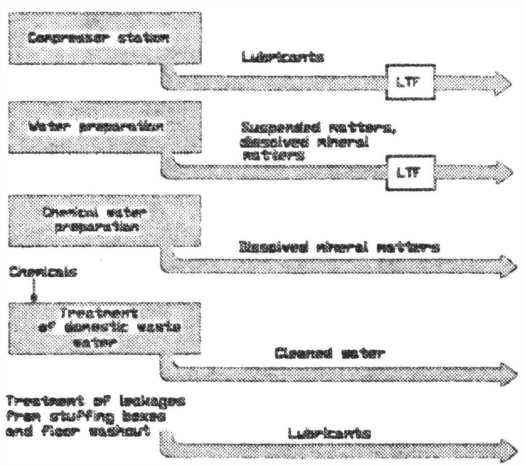

STORM YATER

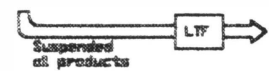

TERKALLY POUUTED VATER

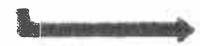

LT - -

Fig. 1. Block-diagram of effluent flows distribution from kraft pulp production. 
All substances getting into effluents may be conventionally reduced to 5 groups in accordance with the block diagram given in Fig. 1:

- Organic matters segregated from the wood during mechanical and chemical processing;

- Suspended matters in the form of bark and fiber formed in the process of mechanical treatment of the wood, production of the pulp, wood and secondary fiber stock, paper and cardboard;

- Mineral and organic substances getting into effluents when used as chemicals for dissolution of wood components, extraction of residual lignin during bleaching, in the composition of paper and cardboard;

- Chemicals getting into effluents when used in the process of water preparation for fresh water coagulation, in the process of chemical water preparation for boilers, in the treatment industrial and domestic waste water (substances containing aluminum, iron, synthetic surfactants)

- $\quad$ Suspended matters, lubricants and oil products with storm water as well as from pump stuffing box sealing and bearing cooling.

In the process of kraft pulp production takes place the dissolution of wood with the cooking liquor, which is the alkaline solution of mineral salts. A part of the wood components, in some cases up to $50 \%$ passes into cooking solution, which is separated from the pulp in the process of its washing. The organic matters that passed from the wood into solution include the sulfate lignin, lower alcohols and odorous sulfur-containing compounds, lower fatty (volatile) acids (in the form connected with sodium), hydroxy-acids, lactones and hydrocarbons, as well as resinous substances and phenol compounds. These substances are the potential pollutants of aqueous medium, which is the determining factor of the impact of the pulp and paper industry on the water bodies.

The amount of organic substances getting with the black liquor into effluents in the kraft pulp production is determined by the degree of the liquor takeout during pulp washing as well as accidental overflow of the black liquor, which may occur at various operations of the chemicals regeneration closed cycle.

In international Recommendations the standard of pollutant discharge with the effluents as the black liquor and accompanying organic substances is represented by the integral index chemical oxygen demand (COD) in unbleached pulp production.

The individual components of black liquor are in certain interrelationship with each other, including COD. Therefore the impact of organic matters on the discharge in the process of unbleached pulp production is possible only through greater or lower takeoff of black liquor both in the pulp washing and in the chemicals regeneration cycle during treatment of these liquors, which corresponds to the greater or lower discharge of organic matters with the effluents as per COD index.

The second source of organic matters in effluents in the production of unbleached kraft pulp is the odorous condensates - the product of condensation of ebullition vapors, formed in the black liquor cooking. In odorous condensates are concentrated the volatile toxic substances, such as methylmercaptan, dimethydilsulfide, dimethylsulfide, hydrogen sulfide, methanol, volatile phenols, terpenes and other compounds. These substances are characteristic for the kraft pulp production. The odorous condensates are the major source of sulfur compounds in the enterprise effluents. Therefore the local treatment of odorous condensates is the solution the realization of which reduces decidedly the pollution of the effluents with the abovementioned substances.

The third source of organics in effluents are the filtrates from the pulp bleaching stage. Except the substances that came over from the wood into cooking liquor these filtrates at the bleaching stage are supplemented with soluble organic substances and chlorine-organic compounds. 
The pollution of effluents after bleaching stage is determined by the bleaching chemicals used. In international HELCOM Recommendations the pollutants in the effluents after the bleached kraft pulp production are characterized by COD and AOH. Simultaneously with limitations of discharge by these indices are introduced the limitations of gaseous chlorine use as the bleaching agent.

The individual substances of bleaching chemicals are in correlation dependence on COD value. The reduction of $\mathrm{COD}$ and $\mathrm{AOH}$ values in effluents is achieved by reduction of the unbleached pulp $\mathrm{K}$ number, i.e. the reduction of residual lignin content in the pulp before bleaching.

The reduction unbleached pulp $\mathrm{K}$ number creates the necessary prerequisites for more favorable conditions of the bleaching process: the use of chlorine dioxide as bleaching chemical (ECF) exclusion of the use of chemicals containing chlorine compounds (TCF). These processes allow to reduce the bleaching chemicals consumption and losses of chemicals. At the same time the prerequisites are created for removal of a part of organic matters and bleaching filtrate chemicals together with the black liquor into the chemicals recovery system, which reduces the number of effluents and their amount. With conversion to TCF pulp bleaching no chlorine organic compounds are formed.

Except the limitations of discharge by COD index in the production of kraft and sulfite pulp the international Recommendations limit also the formation of nitrogen and phosphorus compounds introduced in the process of the biological treatment proportionally to the normalized COD index. The normalization of biogenic substances in the treated effluents requires more efficient use of biogenic salts introduced by improving the mass transfer in the treatment process.

The normalization of biogenic substances by the indices total phosphorus $\left(\mathrm{P}_{\text {Tot. }}\right)$ and total nitrogen $\left(\mathrm{N}_{\text {Tot. }}\right)$, and also in some cases of ammonium, nitrate and nitrite nitrogen is explained by the necessity to prevent the intensive processes eutrophication of water bodies, which upset the oxidation - reduction balance. The pulp and paper industry effluents after biological treatment are enriched with the forms of nitrogen and phosphorus consumable by algae. The biogenic load determines also the tropic level of the water body. For each individual water body have to be found the qualitative dependencies between sanitary characteristics and the tropic state, which will allow considerably to start the environmental normalization in the form of regional standards differentiated by the type of water body.

One of basic criteria for selection of the characteristics to be normalized is its sensitivity to the man's impact, in particular, to various types of effluents by complex and integral indices. This makes it necessary to determine the variation limits of the factors that may at the least be checked this way or other and at the most be controlled in the technological process taking into consideration environmental and economical performances.

In the international Recommendations concerning the discharge of pollutants with effluents from industrial enterprises is introduced the notion "best available technology ", which reflects the latest developments in technology, equipment, production methods capable of meeting the discharge standards by COD and other specific integral characteristics.

For the kraft pulp production to the "best available technology" belong:

- Dry wood debarking with minimum effluents discharge from the process

- Closed system of cleaning and screening of pulp

- Arrangement of the system of collection of leakages and overflows of liquors and chemicals to be reused in the process

- High degree of the pulp delignification before bleaching using the oxygen delignification step

- Efficient pulp washing 
- Making the bleached pulp production liquid flows a closed circuit and turning a part of effluents to the chemical regeneration cycle.

- Treatment of heavily polluted odorous condensates by the method of thermodesorption with the steam and reused of the treated condensates in the process instead of the fresh hot water

- Use in the production when possible the easily biodegradable environment friendly chemicals

- Use of the two-stage effluent treatment

The combination of the techniques of "best available technology" allows to achieve the regulated levels of pollutants discharge with the effluents formulated in the international Recommendations and given in the Table 1.

The requirements for the discharge of suspended matters, oil products and lubricants can be met through the local effluent treatment.

The method of the basin normalization discussed in this paper considering peculiarities of the industry may be used for optimization of the load using as an example the transfrontier water system Saima - Vuoksa. The load in this system has the same characteristic - the predominant pollutants are from the pulp and paper facilities throughout the entire basin, which has to determine the water management policy at intergovernmental level. In particular, the scheme of formulization and realization of comprehensive water protection actions by the prioritizing characteristics is proposed, allowing to distribute the load between all water users: on the one hand considering the environmental capacity of each basin section, on the other hand basing on the achievable technologies.

Thus, the proposed scheme of load optimization for transfrontier water bodies is at the present stage the compromise between the emission standards and environmental norms and is basing on the practically achievable technical solutions.

The major problem both for an example under consideration and for the basins with the predominant impact of various industries, social services or agriculture is the lack of data for estimation of the water body environmental capacity and the degree of mastering by the industries of the "best available technology".

For the comprehensive intergovernmental evaluation and justification of quotas of the load according to the proposed scheme by the integrated indices and first of all by COD additional data are necessary, indicating the conformity of all enterprises of the water system to the "best available technology", aimed at achievement of regulatory standards of pollutant discharge in the effluents. Besides, for the practical solution of the problem it is necessary to formulate the intergovernmental evaluation of environmental capacity of entire water system both by integrated indices and by specific pollutants characteristic for pulp and paper industry. For this end for the example in question the additional investigations of the background characteristics in the upper part of Saima and in the upper part of Vuoksa are necessary using the priority indices, including biotesting. 


\section{Norms of pollutants discharge with the effluents of sulfite and kraft pulp production} (HELCOM Recommendations 17/8 and 17/9)

\begin{tabular}{|c|c|c|c|c|c|c|c|c|c|c|c|}
\hline \multirow{3}{*}{ No } & \multirow{3}{*}{ Index } & \multicolumn{4}{|c|}{ Sulfite pulp production, $\mathrm{kg} / \mathrm{t}$ of pulp } & \multicolumn{6}{|c|}{ Kraft pulp production, $\mathrm{kg} / \mathrm{t}$ of pulp } \\
\hline & & \multicolumn{2}{|c|}{$\begin{array}{l}\text { "Old" } \\
\text { enterprises } 1)\end{array}$} & \multicolumn{2}{|c|}{$\begin{array}{l}\text { "New" } \\
\text { enterprises } 2)\end{array}$} & \multicolumn{2}{|c|}{$\begin{array}{l}\text { "Old" enterprises for } \\
\text { countries with advanced } \\
\text { industry" }\end{array}$} & \multicolumn{2}{|c|}{$\begin{array}{l}\text { "Old" enterprises for } \\
\text { developing countries }\end{array}$} & \multicolumn{2}{|c|}{$\begin{array}{l}\text { "New" } \\
\text { enterprises 2) }\end{array}$} \\
\hline & & Bleached & $\begin{array}{l}\text { Un- } \\
\text { bleached }\end{array}$ & Bleached & $\begin{array}{l}\text { Un- } \\
\text { bleached }\end{array}$ & Bleached & $\begin{array}{l}\text { Un- } \\
\text { bleached }\end{array}$ & Bleached & $\begin{array}{l}\text { Un- } \\
\text { bleached }\end{array}$ & Bleached & $\begin{array}{l}\text { Un- } \\
\text { bleached }\end{array}$ \\
\hline 1 & 2 & 3 & 4 & 5 & 6 & 7 & 8 & 9 & 10 & 11 & 12 \\
\hline 1. & COD & 70 & 45 & 35 & 20 & 30 & 15 & 35 & 20 & 15 & 8 \\
\hline 2. & $\mathrm{AOH}$ & 0,5 & - & 0,1 & - & 0,4 & - & 0,4 & - & 0,2 & - \\
\hline 3. & $\mathbf{P}$ & 0,08 & 0,06 & 0,04 & 0,4 & 0,04 & 0,02 & 0,04 & 0,02 & 0,02 & 0,01 \\
\hline 4. & $\mathrm{~N}$ & 0,7 & 0,6 & 0,4 & 0,3 & 0,4 & 0,3 & 0,4 & 0,3 & 0,35 & 0,25 \\
\hline
\end{tabular}

Note:

1) For countries with advanced industry the limitations are introduced from the year 2000; for developing countries from 2005.

2) Limitations are introduced starting year 1997. 


\section{REFERENCES}

1. Shishkin, A.I. (1995) Principy mejgosudarstvennogo regulirovania vodopol'zovania na primere Ferganskoi doliny (Principles of interstate regulation of water use on an example of Fergana valley). - Monitoring. Bezopasnost' zhiznedeyatel'nosti (Monitoring. Safety of vital activity) 4 , pp. 22-25.

2. Shishkin, A.I. (1998) Water resource model: environment management and principles of future bio-politics. In: Proceedings of the 3rd International Conference "Danube River Bonds", Bratislava, pp. 356-364.

3. Ministry of Natural Resources of Russian Federation (2001) Sbornik Rekomendaci Hel'sinskoi Komissii. Spravochno-metodicheskoe posobie (The Collected Helsinki Commission Recommendation. The reference manual). Ministry of Natural Resources of Russian Federation, St Petersburg, Russia. 